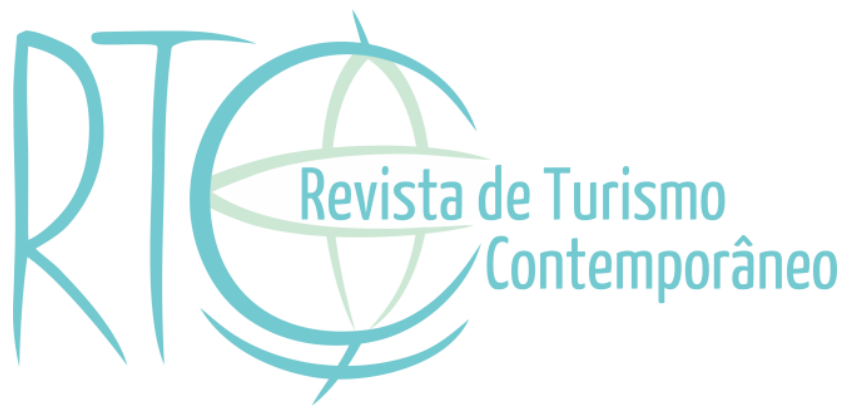

\title{
A evolução do conceito de marketing e sua aplicação no turismo: simetrias evolutivas, assimetrias temporais
}

\section{The evolution of the marketing concept and its application in tourism: evolutionary symmetries, temporal asymmetries}

Sérgio Luiz do Amaral Moretti

Professor do Programa de Mestrado e Doutorado em Hospitalidade da Universidade Anhembi, Morumbi/SP, Brasil

E-mail: sergiomoretti@uol.com.br

Sérgio Luís Ignácio Oliveira

Professor do Mestrado Profissional de Gestão em Alimentos e Bebidas da Universidade Anhembi, Morumbi/SP, Brasil

E-mail: slmarketing@uol.com.br

Claudio Gonsalves de Souza

Professor e Coordenador Adjunto nos Cursos de Administração e Processos Gerencias na Universidade Anhembi, Morumbi/SP, Brasil

E-mail: claudio.gonsalves@gmail.com

Artigo recebido em: 26-07-2017

Artigo aprovado em: 27-04-2018 


\section{RESUMO}

No decorrer de mais de cem anos o Marketing passou por várias transformações conceituais, pensamentos, filosofias empresariais e formas de relacionamento com o mercado. $\mathrm{O}$ artigo tem como objetivo apresentar a evolução dos conceitos de Marketing avaliando suas intersecções com o Turismo. Para tanto, realizou-se uma pesquisa exploratória de cunho historiográfico e bibliográfico que usou como exemplo os trabalhos publicados nos seminários anuais da Associação Nacional de Pesquisa e Pós-graduação em Turismo Anptur, Brasil, no período de 2011 a 2015. O levantamento resultou em 143 trabalhos de Marketing sobre um total de 783 apresentados durante o período, 18\% do total. Por outro lado, na área de Negócios, Marketing representou 47\%. A descoberta mais relevante do estudo foi que o item Pesquisa, com $42 \%$ dos trabalhos foi o que mais se destacou na produção de Marketing aplicado ao Turismo. Houve um aumento de 2,5 trabalhos para o período de 2011-2015 (27 artigos) sobre o período de 2006-2010 (11 artigos). O resultado leva a acreditar que a pesquisa nacional de Marketing, enquanto forma de entender o Turismo nacional, está se consolidando, fato demonstrado pelo foco em novas investigações, das quais se destaca o mundo digital.

Palavras-chave: Marketing. Evolução de Conceitos de Marketing. Turismo. Marketing Turístico. Pesquisa em Marketing.

\section{ABSTRACT}

In the course of over a hundred years Marketing has undergone several conceptual changes, thoughts, business philosophies and forms of relationship with the market. The article aims to present the evolution of the concepts of Marketing evaluating its intersections with Tourism. Therefore, an exploratory research historiographical and bibliographical nature which used as an example the works published in the annual seminars Anptur between 2011 and 2015. The survey resulted in 143 jobs Marketing on a total of 783 submitted during the period, $18 \%$ of total. On the other hand, in the field of business, Marketing represented $47 \%$. The most important finding of the study was that the item search with $42 \%$ of the work was the one that stood out in the production of Marketing applied to Tourism. There was an increase of 2.5 jobs for the period 2011-2015 (27 articles) over the period 2006-2010 (11 articles). The result leads to believe that the national search in Marketing, as a way to understand the national tourism, consolidates, evidenced by the focus on new investigations, of which highlights the digital world.

Keywords: Marketing. Evolution of Marketing Concepts. Tourism. Tourism Marketing. Marketing Research. 


\section{INTRODUÇÃO}

O Marketing surgiu como área de conhecimento no início do século XX em universidades norte-americanas. O objetivo da nova disciplina era investigar soluções para os problemas que as empresas enfrentavam em seus processos de distribuição. Naquele momento as empresas já tinham a consciência de que necessitavam chegar de forma eficiente e lucrativa aos seus mercados consumidores (Arantes, 1975; Bartels, 1976; Butler, 1914; Maynard, 1941; Lazer, 1966; Sandhussen, 2003; Surface, 1940; Wilkie \& Moore, 2003; Vargo \& Lusch, 2004).

Após esse início o Marketing passou, no decorrer de mais de cem anos de história, por várias transformações em termos de conceitos, pensamentos, filosofias empresariais e maneiras de se relacionar com o mercado (Kotler \& Keller, 2012; Lusch, 2007; Sheth, Gardner \& Garrett, 1988; Vargo \& Lusch, 2004; Wilkie \& Moore, 2003). Tal evolução perseguia responder às inúmeras demandas apresentadas pelo trabalho, junto aos clientes, consumidores finais e intermediários, além dos concorrentes. Essas mudanças conceituais foram responsáveis por garantir a importância da nova disciplina e permitiram resolver problemas pontuais que se apresentavam às empresas de diversos setores como foi o caso do Turismo após a década de 1950.

O mercado adotou novos formatos de negócios e, por seu lado, os consumidores evoluíram na sua lida diária com os produtos, talvez, ainda mais rápidos. O contato entre as duas partes separadas, mas imprescindíveis, para a troca, implica na adoção de novos canais de comunicação e distribuição.

Recentemente Lusch (2007) propôs que a disciplina caminhou por três estágios, nos últimos cem anos: 1) To Marketing: oferta e capacidade produtiva são escassos, assim o objetivo principal é levar os produtos para o mercado, juntando as duas partes separadas, porém responsáveis pela compra, verdadeira unidade de medida do mercado; 2) Market(ing) to: oferta e capacidade produtiva são abundantes, portanto, agora a missão principal é identificar clientes e consumidores e realizar o Marketing para eles. $\mathrm{O}$ cliente assume o centro do processo; 3) Market(ing) with: os serviços dominam o espectro econômico e provocam o início do estágio mais avançado; as empresas precisam enxergar o cliente como endógeno e parceiro, ajudando na cocriação dos produtos (incluindo os serviços). Trata-se da fase do relacionamento.

O artigo tem como objetivo apresentar a evolução dos conceitos de Marketing avaliando suas intersecções com o Turismo. Trata-se de uma pesquisa exploratória de cunho historiográfico e 
bibliográfico que usou como fonte de dados trabalhos publicados nos seminários anuais da Associação Nacional de Pesquisa e Pós-graduação em Turismo - ANPTUR, Brasil, no período de 2011 a 2015.

Adicionalmente, busca-se demonstrar como o processo de institucionalização do Marketing contribuiu para sua consolidação como área de estudos, permitindo uma independência de áreas mais tradicionais como a Economia, Administração e Sociologia, se consolidando como uma importante área de conhecimento, tanto nos meios acadêmicos, quanto empresariais. $\mathrm{O}$ mesmo percurso se observou no Turismo, embora esta simetria tenha sido temporalmente separada por quase meio século. A parceira com o Marketing demonstra nos últimos anos a importância crescente do Turismo, Hospitalidade e Viagens integrados como um grande mercado.

A contribuição deste estudo vai no sentido de contribuir para mostrar a evolução do interesse pelo Marketing nos estudos de Turismo exemplificado pelo maior evento sobre o setor no Brasil, a Anptur.

Para o desenvolvimento dessa temática, primeiramente, será apresentado o cenário historiográfico do Marketing, as mudanças conceituais, ou escolas do pensamento do Marketing. Posteriormente, se contemplará o Marketing aplicado ao Turismo, a metodologia da pesquisa, a análise dos principais resultados e as considerações finais.

\section{EM BUSCA DE UM LUGAR PARA O MARKETING}

Conforme Moretti e Toledo (2015), a proposta de explicar a atuação do Marketing a partir de três macro dimensões (Toledo, 1994) possibilita compreender com maior precisão alguns elementos que permeiam a sua definição quais sejam: 1) Dimensão funcional: finalidade do Marketing; 2) Dimensão gerencial: gerência de Marketing; e, 3) Dimensão filosófica: orientação que dá suporte ao modelo de negócios da empresa. Nas palavras dos autores:

a orientação ou filosofia adotada pela empresa (dimensão filosófica) constitui o alicerce sobre o qual será construído, em amplitude e profundidade, o processo gerencial de Marketing (dimensão gerencial) para atendimento de sua função essencial: promover, estimular e facilitar a troca (Moretti \& Toledo, 2015, p. 612).

Pode-se perceber a trilha percorrida, em busca de uma identidade para o Marketing, a partir da análise da definição proposta pela AMA em 1937 “(...) estudo sistemático das atividades que encaminham o fluxo de produtos, bens e serviços aos consumidores finais industriais e comerciais". Comparada com a atual demonstra que tal fato não deve causar 
surpresa, posto se tratar de disciplina voltada para o conhecimento do mercado para nele atuar com maior probabilidade de sucesso. Neste artigo adotou-se a definição de Marketing da American Marketing Association, aprovada em julho de 2013 pelo Board Directors:

Marketing is the activity, set of institutions, and processes for creating, communicating, delivering, and exchanging offerings that have value for customers, clients, partners, and society at large. (AMA, 2013)

Na verdade, conforme apontaram Costa (2008) e Silva (2010) a evolução se deu às custas de muitos debates, principalmente durante as décadas de 1980 e 1990, que se concentraram na busca de um escopo que orientasse as pesquisas vindouras. Muito esforço foi feito para encontrar uma definição que elevasse o Marketing ao status de teoria. Graças a este movimento, o século XX viu surgir uma nova combinação de elementos na formulação de modelos interpretativos, desenvolvidos por inúmeros pesquisadores de renome (Bagozzi, 1986; Baker, 2000a, 2000b; Bartels, 1976; Kotler \& Keller, 2012; Hunt, 1983; Sheth et al., 1988; Smithee, 1997).

Tomando como base Baker (2000, 2000b), a partir da década de 1990 o foco dos estudos de Marketing se desloca do comportamento do comprador e da análise de oportunidades estratégicas (Bagozzi, 1986) para os aspectos do relacionamento, à medida que o setor de serviços passava a ser a atividade de maior crescimento até superar a indústria. A partir do momento em que o Marketing teve que se ater às ofertas intangíveis, características dos serviços, pouco a pouco os estudos foram se concentrando, cada vez mais, nas trocas e nas relações entre produtor e comprador (Sheth et al.,1988; Srivastava, Shervani \& Fahey, 1999).

Uma boa forma de entender a evolução do Marketing é por meio da abordagem das "Eras" ou "Orientações das Empresas", por exemplo, a Era da Produção, de Vendas e do Marketing. Este é o esquema adotado pela maioria dos pesquisadores e por falta de espaço, se deixará para outra oportunidade a interessante comparação entre os modelos de Bartels (1976) e Wilkie e Moore (2003).

A Era da Produção (1900-1930) expressava o foco das empresas no sentido de escoar a produção em massa, resultado das revoluções industriais precedentes. Nessa fase, a única preocupação era disponibilizar seus produtos ao mercado, sem preocupação com as necessidades dos consumidores (Cobra, 1992; Keith, 1968; Kotler \& Keller, 2012; Oliveira, 2007). O contexto era de uma demanda maior que a oferta e a única preocupação era descobrir técnicas mais eficientes para os produtos chegarem às mãos dos clientes. 
Na Era das Vendas (1930-1950) as organizações deslocaram o foco para estratégias de promoção e vendas. Ao contrário do período anterior, agora a oferta supera a demanda e se era uma questão de sobrevivência vender, cada vez mais. Os pesquisadores da época acreditavam que os consumidores não comprariam seus produtos se não existisse um esforço substancial em sua promoção (Bartels, 1976; Cobra, 1992; Keith, 1968; Kotler \& Keller, 2012; Oliveira, 2007; Wilkie \& Moore, 2003).

A Era do Marketing (1950 em diante) mostra as empresas centradas na satisfação das necessidades e desejos dos consumidores. No final da década de 1940 e início da década de 1950 surge o conceito atual de Marketing incentivado pela descoberta da aplicação das Ciências Sociais nos estudos sobre o mercado, com a inclusão da Sociologia e a Psicologia às tradicionais, Economia e Administração, essa em plena era da Administração Científica. Subsidiado pelos estudos em Psicologia aplicados à Administração e as Teorias da Comunicação, que permitiam melhor entendimento dos consumidores, surge o conceito atual de Marketing. A expressão melhor acabada desta fase é a centralidade do consumidor no processo de negócios (Arantes, 1975; Bartels, 1976; Keith, 1968; Kotler \& Keller, 2012; Lazer, 1966; Sandhussen, 2003; Vargo \& Lusch, 2004; Wilkie \& Moore, 2003).

Um denominador comum entre todas as décadas é que a cada desafio enfrentado pelas empresas, em função das modificações de mercado, se dá em torno do Marketing Mix, ou seja, dos quatro vetores pelos quais uma empresa se relaciona com seu mercado: produto, preço, praça e promoção. Nota-se, igualmente que as modificações conceituais do Marketing, principalmente no seu percurso em se tornar uma disciplina acadêmica buscaram a melhor forma de relacionamento entre empresas e consumidores. Ao final da década de 1990, os estudos denominados pós-modernos de Marketing, de acordo com as premissas de Firat e Venkatesh (1993) contaram com novos elementos, dentre os quais, os fundamentos da hiperrealidade, ou seja, da virtualidade pura, no qual a realidade pode ser recriada para uso e consumo individual dentro da perspectiva da cocriação, principalmente no mercado de bens e serviços que são fortemente afetados pela transformação do consumidor em coprodutor (prosumer).

A Figura 1 (a seguir), proposta por Kotler, Kartajaya e Setiawan (2010) mostra, no ver dos autores, como esta evolução se processou, acrescentando os focos que orientaram a reflexão sobre a disciplina, em cada década desde 1950.

Para os objetivos desse artigo, deve-se destacar que a vertente do Marketing de Serviços é tarefa importante no sentido de relacioná-lo com a atividade de Turismo e 
Hospitalidade. Para isso recupera-se a questão essencial de Sheth, Gardner e Garrett (1988), para quem esta evolução transita pela indagação sobre quais são as diferenças entre Marketing de bens e serviços (ambos são considerados produtos).

Em Serviços, as empresas, primeiro fazem uma promessa, de fato, vendem uma expectativa cuja aproximação com a realidade, apenas poderá ser comprovada no momento da sua entrega ao comprador (cliente ou consumidor final). É o caso de uma viagem, uma estadia ou um atendimento médico. Isto é o que se denomina "momento da verdade" (Grönroos, 1994, p. 12). Dessa forma "a qualidade do serviço prestado só pode ser considerada satisfatória se o serviço realizado, e percebido pelo cliente, for de qualidade excepcional, superando as expectativas do usuário".

Figura 1- Evolução do Marketing a partir da década de 1950

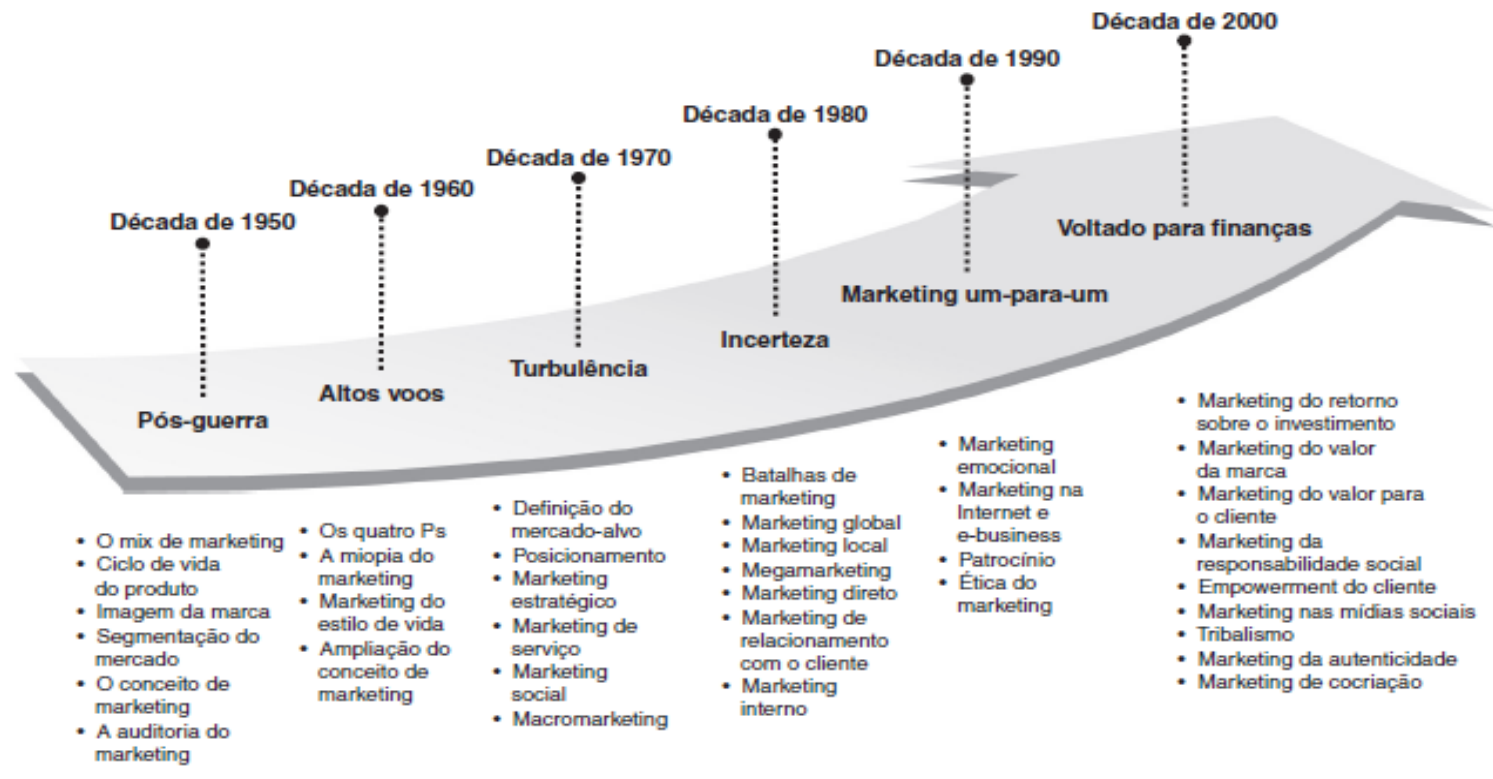

Fonte: Kotler, Kartajaya e Setiawan (2010, p.32)

Para Moretti e Toledo (2015), seguindo o pensamento de Srivastava et al., (1999) quanto maior o envolvimento do Marketing com a estratégia empresarial, mais evidente se torna, que deve se concentrar em gerenciar processos-chave geradores de valor, tanto para os clientes, quanto para empresa: desenvolvimento do produto, cadeia de suprimentos e relacionamento com o cliente. Com a dominância crescente dos Serviços, se consolidava a percepção de que o cliente deveria ocupar o centro do negócio.

Contudo, deve ser ressaltado que o cliente forma essas expectativas desde o estímulo dado pelo emissor (provedor do serviço) e processada por todas as suas complexas percepções internas e individuais às quais se podem adicionar as experiências de outros indivíduos por meio de um processo boca a boca. Reside neste ponto a questão principal, implicando em que 
a entrega da oferta deve ser bem próxima possível da prometida para evitar a dissonância causada pelo gap entre uma e outra (Grönroos, 1994 \& Gummenson, 2002).

Para se conseguir uma boa percepção de satisfação do cliente, o controle sobre o continuum do processo deve ser intenso no sentido de garantir a qualidade, não apenas no momento do encontro, mas em todos os níveis, já que as diretrizes da empresa necessitam ser amplamente divulgadas para os funcionários que são responsáveis por sua execução. Robinson e Lynch (2007) propõem, no caso do encontro de serviços (ou hospitalidade), uma visão da empresa em dois níveis: o nível macro, que seria o das diretrizes, normas e valores organizacionais disseminados por toda a empresa e, o nível micro aquele do atendimento em si, o momento real da entrega da oferta prometida.

Para Moretti (2015) a visão do encontro de serviços foi dominada pela síndrome do evento, em detrimento de um processo, conforme se argumentou anteriormente. No parecer do autor, em conformidade com Knutson e Beck (2003) ele é caracterizado por três fases: "1) a pré-experiência do consumo que envolve todos os contatos anteriores ao encontro; 2) o momento do encontro em si, e sua rica disposição de experiências e, 3) o pós-encontro, caracterizado pelos efeitos da retenção da experiência na memória dos clientes" (Moretti, 2015, p. 5). A Figura 2 mostra a relação entre as fases e o continuum do encontro. 
Figura 2 - Processo da Experiência e Relacionamento em Hospitalidade

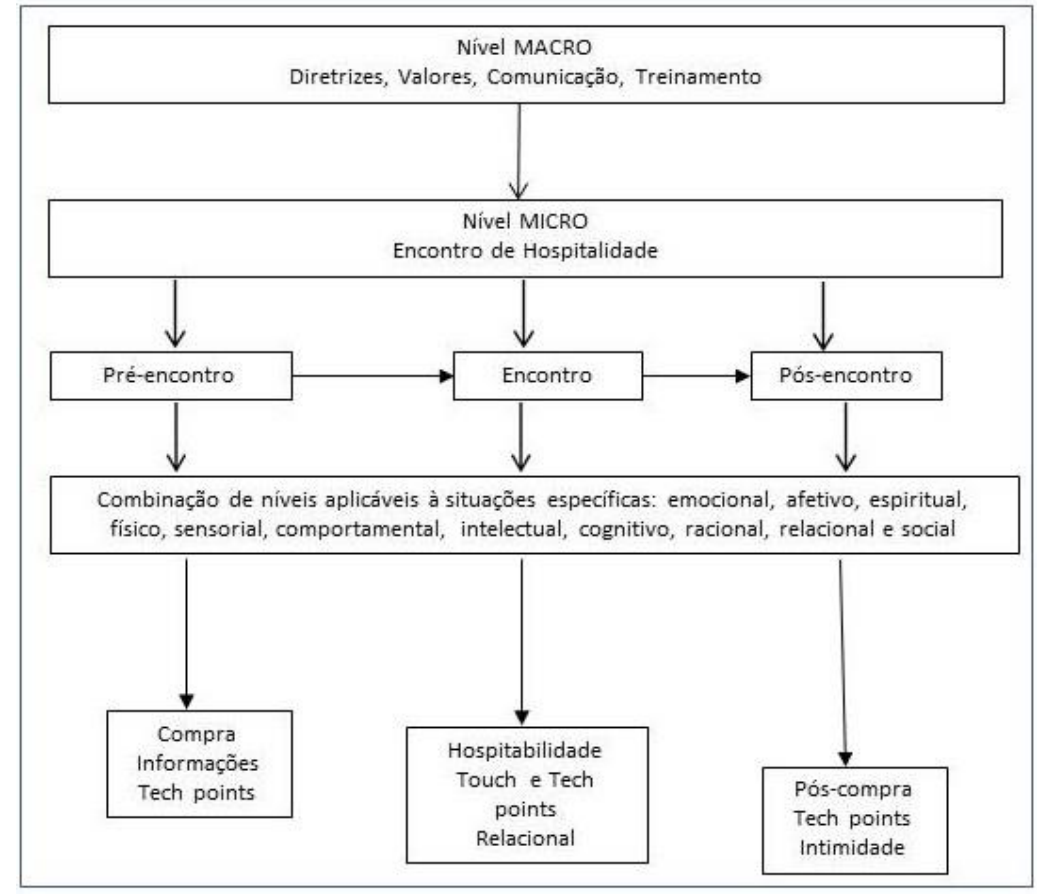

Fonte: Adaptado de Moretti, 2015, p. 15.

Os momentos de contato entre provedor e comprador da oferta de serviços ocorrem em três etapas, na compra, estabelece-se a primeira experiência, que é traduzida pelo acordo em torno da promessa que será entregue no momento do encontro, propriamente dito. Nesta fase a promessa se concretizará ou não gerará a experiência real de consumo; na próxima fase, a da pós-compra, a memória tem seu espaço na criação de uma experiência perene, seja positiva ou não.

Tal argumento é reforçado por Bowie e Buttle (2004); Buhalis e Costa (2006); Cobra (2001); Hsu e Powers (2002); Holloway (2004); Kotler, Bowen e Makens, (1998); Middleton, Fyal, Morgan e Ranchrod (2009); Morrison (2012) todos importantes autores de livros-texto sobre Marketing e Management Turístico em períodos bastante distintos de tempo. Os autores convergem para concordar que a grande oportunidade do setor turístico em termos de negócio é compreender como o Marketing tradicional foi adaptado para Serviços, podendo contar com toda uma tradição de estudos sobre esta importante variante do Marketing como disciplina geral.

Justamente porque, como já argumentado anteriormente, o setor do turismo, visto pela vertente das viagens, hospedagem, ou Marketing de destinos, é pautado pelos fundamentos dos Serviços, já que suas ofertas (produtos) são de natureza intangível (Kotler et al., 1998; Tosun, Okmus \& Fyall, 2008). 
Segundo Holloway (2004), a partir do fim da Segunda Grande Guerra, o turismo começou a se estruturar como uma verdadeira indústria e durante a década de 1960 os segmentos médios de renda se tornaram alvos das grandes empresas, tanto de transporte, quanto de hospedagem. Este foi o momento em que o Marketing começou a trabalhar para ambos os setores em busca da expansão do turismo como um todo.

De fato, tratava-se como ainda o é, uma indústria complexa envolvendo vários tipos de negócios implicando em conciliar estratégias, estilos e objetivos diferentes que necessitavam de harmonização em prol do conjunto (Kastenholz, 2002; Buhalis \& Costa, 2006), assim como as possibilidades de segmentar este mercado para melhor aproveitar suas vantagens (Panosso Netto, 2009). O panorama geral é mostrado na Figura 3.

Figura 3 - Panorama da indústria do Turismo

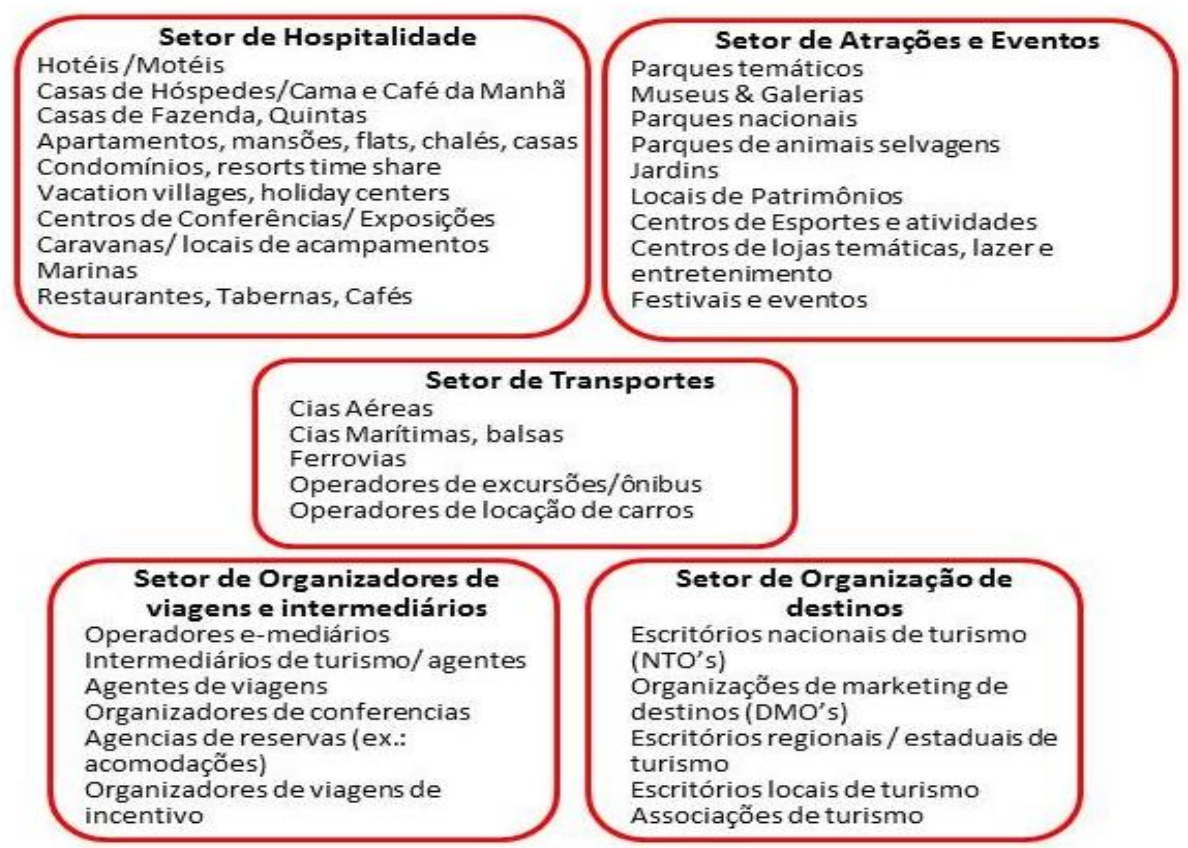

Fonte: Adaptado pelos autores de Middleton; Clarke, 2001, p. 11.

Estes setores se interconectam entre si de uma forma intensa, exigindo uma abordagem sistêmica para ser compreendido em toda sua extensão (Beni, 2006). Tal complexidade é realçada por Lage e Milone (1990) que o exemplificam da seguinte forma: tome-se dois destinos, com dez hotéis no total e duas companhias aéreas para servi-los, apenas neste simples caso temos 40 combinações possíveis. Pode-se, então, imaginar todas as possibilidades que são apresentadas atualmente.

A década de 1960 foi precisamente o momento que Dev, Buschman e Bowen (2010) estabeleceram para iniciar seu interessante estudo sobre o Marketing Turístico a partir das 
publicações da Cornell Hospitality Quarterly. Os autores se propuseram a analisar a evolução do Marketing Turístico buscando categorizar qual era o foco das publicações neste quesito e, para isso dividiram-na em décadas. O percentual de artigos de Marketing sobre os demais passou de $6.1 \%$ na década de 1960 para $18.1 \%$ na década de 2000 .

A pesquisa de Dev et al., (2010) vai ao encontro do que foi discutido anteriormente para o Marketing enquanto disciplina geral. Os autores postulam que o Marketing de Hospitalidade foi além do conceito fundamental de buscar clientes e se tornou um meio de estruturação do negócio em si, motivando consumidores certos para os produtos (serviços) certos e criando valor para eles e as empresas. O Quadro 1 mostra o foco predominante das atividades de Marketing em cada década até o século XXI.

Quadro 1 - Envolvimento de Marketing com a Indústria de Turismo

\begin{tabular}{|c|c|c|}
\hline $\begin{array}{l}\text { Períod } \\
\text { o }\end{array}$ & Foco & Impulsionadores \\
\hline 1960's & $\begin{array}{l}\text { Promoção, } \\
\text { Promoção, } \\
\text { Promoção }\end{array}$ & $\begin{array}{l}\text { Avanço da tecnologia no setor; criação de novas redes de } \\
\text { hotéis; criação do primeiro sistema de reservas automáticas } \\
\text { (Holidex) pelo Holliday Inn. }\end{array}$ \\
\hline 1970's & $\begin{array}{l}\text { Desenvolviment } \\
\text { o de Produto e } \\
\text { Pesquisa de } \\
\text { Mercado }\end{array}$ & $\begin{array}{l}\text { Intensa concorrência; mudança nas exigências dos } \\
\text { consumidores; a construção do primeiro atrium hotel; mais } \\
\text { inovações na automatização das reservas; o setor turístico } \\
\text { atrai o interesse dos pesquisadores de Marketing. }\end{array}$ \\
\hline 1980's & $\begin{array}{l}\text { Gerenciamento } \\
\text { de Receitas e } \\
\text { Desenvolviment } \\
\text { o de Marcas }\end{array}$ & $\begin{array}{l}\text { O setor começa a adaptação de duas décadas de grande } \\
\text { crescimento; novos segmentos de mercado precisavam ser } \\
\text { descobertos; diversos artigos sobre yield management e os } \\
\text { negócios em si. }\end{array}$ \\
\hline 1990's & $\begin{array}{l}\text { Satisfação e } \\
\text { Lealdade do } \\
\text { Consumidor }\end{array}$ & $\begin{array}{l}\text { O setor descobre que custa cinco vezes mais conquistar um } \\
\text { cliente do que mantê-lo; o customer relationship } \\
\text { management começa a ser implantado. }\end{array}$ \\
\hline 2000's & $\begin{array}{l}\text { O Marketing da } \\
\text { Internet }\end{array}$ & $\begin{array}{l}\text { O tema predominante na década foi o web marketing; muitas } \\
\text { transformações na comunicação e na pesquisa de Marketing. }\end{array}$ \\
\hline 2010's & $\begin{array}{l}\text { Movidos pelos } \\
\text { dados }\end{array}$ & $\begin{array}{l}\text { Predomínio da busca dos big data, das redes sociais e a } \\
\text { comunicação por dispositivos móveis. }\end{array}$ \\
\hline
\end{tabular}

Fonte: Adaptado de Dev, Buschman e Bowen (2010). 
Pode-se dizer como base no exposto anteriormente que o processo de evolução do Marketing Turístico foi alimentado por duas vertentes: a própria evolução do Marketing como disciplina geral e a evolução do mercado turístico em particular (Buhalis, 2000; Donaire, Silva \& Gaspar, 2009; Li \& Petrick, 2008; Von Friedrichs \& Gummesson, 2006)

Para os estudiosos deste tema, em particular Krippendorf (2010), o Marketing turístico deve ser analisado a partir das características de um setor que necessita de forte integração em sua cadeia produtiva, principalmente entre as empresas de viagem, hospitalidade e autoridades locais, portanto, envolvendo o macro sistema público e privado, além de nacionais e internacionais. Para Li e Petrick (2008), o setor é multifacetado e implica uma abordagem multidisciplinar, que recentemente além das tradicionais disciplinas como geografia, antropologia e economia recebeu a adesão das disciplinas dos negócios, entre eles o Marketing.

Devido às complexas relações no setor turístico, diversos autores se interessaram por analisar o fenômeno do desenvolvimento do Marketing Turístico, Alcañiz, Simó, Garcia e Herrera (2008) analisaram a publicação de três importantes periódicos internacionais de turismo entre 2004 e 2006 e descobriram que 50\% da produção total em turismo havia sido de artigos de Marketing.

Posteriormente, Machado, Medeiros e Luce (2011) levantaram artigos sobre Marketing de destinos. Pesquisaram nos anais da Anptur o período de 2006 até 2010 e encontraram 56 artigos tratando do tema Marketing utilizando a mesma classificação de Alcañiz, et al. (2008). Brunelli, Macedo-Soares, Zouain e Borges (2010) levantaram cento e trinta e nove periódicos dedicados ao turismo e entorno, da base de dados do Institute for Scientific Information (ISI) e Qualis-Capes no período de 2005 a 2009, descobrindo que dos 1.648 artigos, 568 eram de Marketing, uma participação de 34,5\%.

O Marketing de Serviços oferece um modelo para se pensar o Marketing Turístico bastante adequado, como já argumentado há algum tempo por pesquisadores brasileiros, p.ex. Trigueiro (1999), sobre a segmentação do mercado turístico e Dias e Cassar (2005) sobre a qualidade dos produtos turísticos. Mais recentemente, Da Silva, Flores, Cavalcante e Raye (2012), Pereira, Leite e Flores (2013) e Da Silva, Silva, Cipriano e Matos (2015) escreveram sobre a orientação para Marketing e o Marketing como função, recentemente. Esta produção e a análise bibliométrica dos artigos nacionais são uma forte evidência da importância do tema. 


\section{METODOLOGIA DA PESQUISA}

Trata-se de uma pesquisa exploratória-bibliográfica realizada a partir dos artigos publicados na Anptur entre 2011 e 2015. Seu objetivo foi averiguar a produção do tema Marketing Turístico naquele encontro. Os procedimentos buscaram dar continuidade ao levantamento de Medeiros et al (2011) que realizaram sua pesquisa, nos mesmos anais da Anptur para o período de 2006 até 2010.

Foram selecionados todos os artigos que trataram dos temas relativos à Gestão, Planejamento e Marketing no período, independente se estavam alocados nos GTs reservados a Marketing. Uma pesquisa preliminar revelou que muitos artigos tratavam desses temas mesmo inseridos em outros GTs. Primeiramente, a seleção privilegiou os títulos dos trabalhos e, posteriormente, uma leitura dos resumos mostrou a sua adequação aos objetivos da pesquisa.

A classificação de Alcañiz et al., (2008) contemplou três temas de Marketing: Ambiente, Funções e Pesquisa e, Outros. Este foi o modelo usado por de Medeiros et al (2011). Os autores encontraram 56 artigos de Marketing classificados pelos temas acima descritos. Uma descoberta adicional, mas não menos importante, foi que a classificação pretendida não tinha um ajuste ideal com as temáticas pesquisadas por brasileiros. Os resultados da mencionada pesquisa são apresentados no Quadro 2.

Quadro 2 - Categorização segundo Temáticas de Marketing de Alcañiz et. al
\begin{tabular}{|l|l|l|}
\hline Funções de Marketing & $\mathrm{N}^{\circ}$ artigos & $\%$ \\
\hline Formas diversas de Comunicação & 12 & 21,43 \\
\hline Estratégias de Marketing & 10 & 17,86 \\
\hline Gerenciamento e Planejamento & 4 & 7,14 \\
\hline Canais de Distribuição & 4 & 7,14 \\
\hline Publicidade & 3 & 5,36 \\
\hline Marketing e Novas Tecnologias & 1 & 1,78 \\
\hline Comportamento do Consumidor & 12 & 21,43 \\
\hline Aspectos do Macro ambiente & 4 & 7,14 \\
\hline Análise do Mercado e da Demanda & 3 & 5,36 \\
\hline Pesquisa em Marketing & 3 & 5,36 \\
\hline Total & 56 & 100 \\
\hline
\end{tabular}

Fonte: Adaptado de Medeiros et al (2011)

Os meios de hospedagem apresentam maior destaque na análise dos trabalhos brasileiros, enquanto no estudo de Alcañiz et al., (2008) aparecem depois das pesquisas não 
setoriais. Tal fato pode indicar que as pesquisas aplicadas a setores específicos são mais comuns no contexto brasileiro (Medeiros et al.,2011, p. 9).

Seguindo a própria recomendação de Medeiros et al (2011) que recorreu às lacunas de pesquisa em turismo apontadas por Pike (2008), entre elas o planejamento, comunicação e pesquisa, os autores deste artigo optaram por criar uma taxonomia própria, buscando se adaptar à realidade nacional.

Para os efeitos desta pesquisa foram, portanto, selecionados artigos como foco em Gestão e Stakeholders, Planejamento e Competitividade e Marketing. Por sua vez, estes foram classificados em Comunicação e Propaganda, Gestão e Planejamento, Comportamento do Consumidor e Pesquisa. Este último item se refere a todos os esforços de levantamento de informações sobre o Ambiente de Marketing, relações com o setor público e sazonalidades, que não se encaixavam nos demais itens.

Na próxima seção são apresentados e discutidos os resultados.

\section{ANÁLISE E DISCUSSÃO DOS PRINCIPAIS RESULTADOS}

O levantamento nos anais da Anptur para o período entre 2011 e 2015 resultou em 143 artigos que se adequaram à macro classificação mencionada anteriormente. Os dados servem para mostrar a importância dos temas relativos aos negócios como já havia sido constatado por Bunelli et al (2010) e Dev et al., (2010).

Como se pode perceber na Tabela 1, dentro da área de negócios o tema Marketing é responsável por 47\% da produção de Negócios no período 2011-2015 e por 18\% da produção total dos artigos aprovados para o encontro.

Tabela 1 - Produção de artigos da área de Negócios na Anptur, período 2011-2015

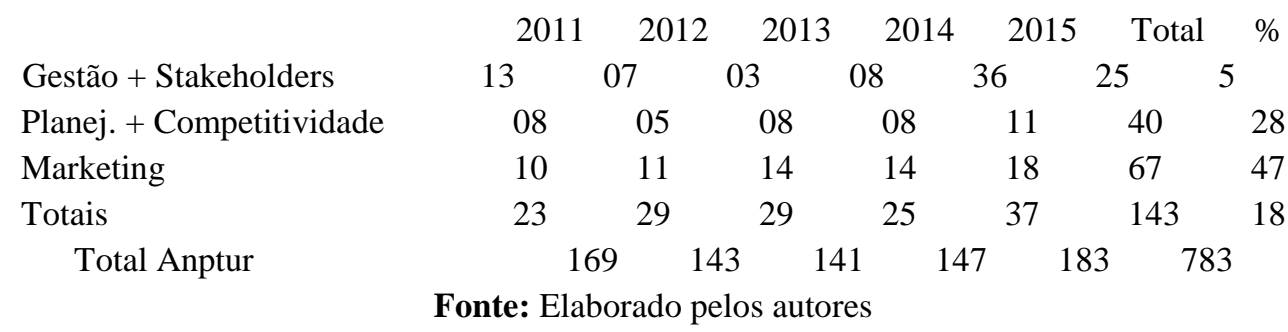

A classificação dos artigos de Marketing destacados da área de Negócios mostra que a Pesquisa é o mais importante dos itens de Marketing, indicando que a busca de informações se tornou um tema recorrente para os pesquisadores da área. $\mathrm{O}$ resultado segue na linha 
apontada por Pike (2008) e Dev et al., (2010) para o foco das pesquisas na década de 1970 nos anais da Cornell Hospitality Quarterly.

A pesquisa nacional estará agora entrando nesta área que já foi resolvida pelos norteamericanos há quarenta anos? Se tomarmos os resultados de Medeiros et al., (2011) que descobriram, apenas 3 artigos sobre pesquisa no período de 2006-2010, parece que sim.

O Gráfico 1 mostra mais claramente o destaque do crescimento da produção da área de Negócios e a contribuição de Marketing para esse resultado.

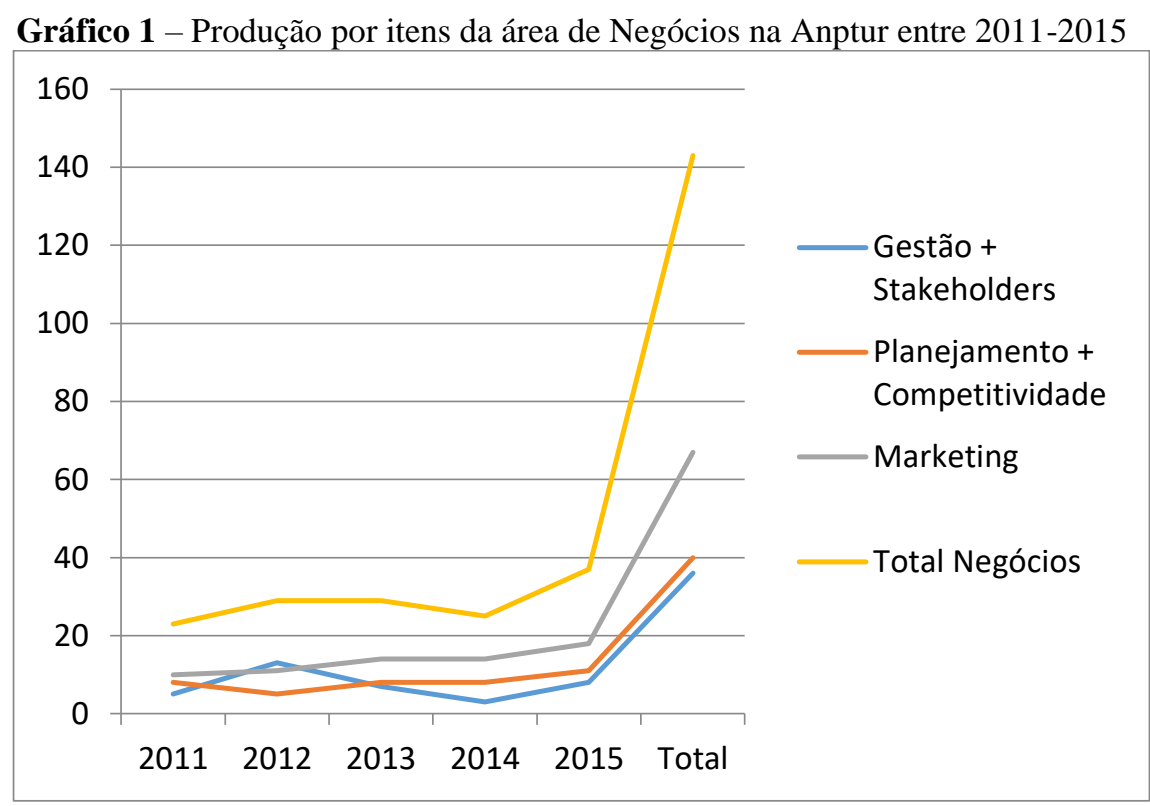

Fonte: Elaborado pelos autores

Porém, é preciso se descontar as diferentes taxionomias adotadas, um exercício sobre os dados do Quadro 3 mostra que se somarmos os itens Pesquisa em Marketing (3) com Marketing e novas tecnologias (1), Aspectos do Macro ambiente (4) e Análise do Mercado e Demanda (3) obteremos como resultado 11 artigos classificados em Pesquisa. Este último item na classificação adotada por este artigo poderia ter sido incluída em Comportamento do Consumidor, conforme o caso. Mas consideraremos mesmo assim como Pesquisa para desenvolver o argumento.

Descontados os diferentes critérios, como se disse, houve um crescimento de 11 artigos para o período 2006-2010, para 27 artigos no período 2011-2015. Um resultado bem considerável que leva a acreditar que a pesquisa nacional entra em um momento de descobertas de novos rumos para investigações. Os resultados podem ser observados no Quadro 3. 
Quadro 3 - Artigos da Classificação de Marketing no período da pesquisa

\begin{tabular}{|c|c|c|c|c|c|c|c|}
\hline & 2011 & 2012 & 2013 & 2014 & 2015 & Total & $\%$ \\
\hline $\begin{array}{c}\text { Comunicação e } \\
\text { Propaganda } \\
\end{array}$ & & & 5 & 2 & 2 & 9 & 13 \\
\hline $\begin{array}{c}\text { Gestão e } \\
\text { Planejamento }\end{array}$ & 3 & 3 & 2 & 4 & 3 & 15 & 22 \\
\hline $\begin{array}{l}\text { Comportamento } \\
\text { do Consumidor }\end{array}$ & 3 & 5 & & 2 & 6 & 16 & 23 \\
\hline Pesquisa & 4 & 3 & 7 & 6 & 7 & 27 & 42 \\
\hline Total & 10 & 11 & 14 & 14 & 18 & 67 & \\
\hline
\end{tabular}

Fonte: Elaborado pelos autores

Da mesma forma que Marketing impulsionou a produção para cima, quando considerada a área de Negócios, o item Pesquisa provocou o mesmo efeito na produção de Marketing. Pode-se ver que ela representou $42 \%$ da produção deste item. O resultado está de acordo $\mathrm{cm}$ as pesquisas mostradas anteriormente, especificamente a de Alcañiz, et al., (2008). O gráfico 2 mostra o resultado comparado entre os itens de Marketing.

Gráfico 2 - Produção dos itens de Marketing para o período 2011-2015 na Anptur.

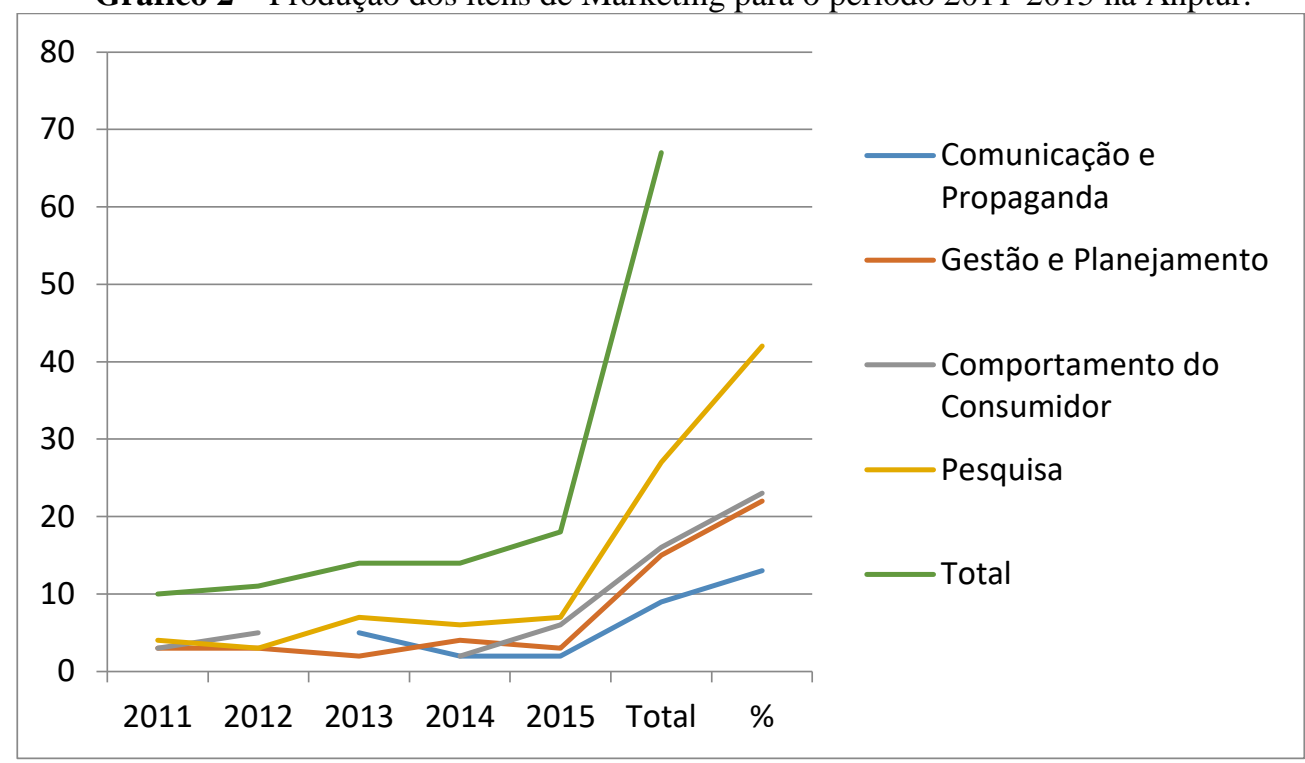

Fonte: Elaborado pelos autores

O destaque entre os temas da categoria Pesquisa, já considerados os cinco anos do período foi o conjunto de temas variando entre internet, Marketing digital, redes sociais, eMarketing e aplicativos para facilitar buscas e localizar lugares, o total observado foi de 11 Revista de Turismo Contemporâneo - RTC, Natal, v. 6, n. 1, p. 129-150, jan./jun. 2018. 
trabalhos, cerca de $41 \%$ da categoria. Tudo leva a crer que a continuar o interesse por estes temas, a pesquisa nacional expressada pelos trabalhos aprovados na Anptur deverá avançar de forma definitiva para o mundo digital. Espera-se com isso que tragam novos entendimentos sobre este campo e sua utilização em Hospitalidade, Turismo e Viagens.

\section{CONSIDERAÇÕES FINAIS}

Este artigo teve como objetivo apresentar o contexto que permeou os primeiros estudos em Marketing, e evidenciar como a área procurou responder às demandas de diversas áreas, especialmente o Turismo, visto como o tema que engloba Hospitalidade e Viagens. Para isso, foi realizada uma pesquisa historiográfica, bibliográfica e feita a análise de artigos publicados na Anptur entre 2011 e 2015.

Para os efeitos desta pesquisa foram selecionados trabalhos como foco em Gestão e Stakeholders, Planejamento e Competitividade e Marketing, foco deste artigo. Estes, por sua vez, foram classificados em Comunicação e Propaganda, Gestão e Planejamento, Comportamento do Consumidor e Pesquisa.

A pesquisa bibliográfica mostrou diversos pesquisadores buscando compreender o fenômeno do Marketing aplicado ao complexo setor turístico, principalmente o período em que efetivamente se começou a aplicar os conceitos e ferramentas de Marketing no setor.

A evolução do Marketing como disciplina foi abordado a partir das três Eras: Produção, Vendas e Marketing que dão nome ao foco que as empresas davam a suas atividades de atender ao mercado consumidor. Viu-se, igualmente que o Marketing evolui na mesma esteira que os mercados, acompanhando as crescentes necessidades que sua complexificação impunha.

$\mathrm{Na}$ verdade, percebe-se um denominador comum, já que as históricas modificações conceituais do Marketing, principalmente em seu caminho para se tornar uma disciplina acadêmica buscaram a melhor forma de relacionamento entre empresas e consumidores.

A abordagem das Eras de Marketing vai ao encontro das pesquisas que trataram de relacionar a produção de Marketing com a predominância de temas nos periódicos que publicam neste campo de pesquisa. Viu-se que o Marketing Turístico se comportava da mesma forma que o Marketing quando visto como disciplina geral.

A análise dos artigos publicados na Anptur, no período de 2011-2015 mostraram que a publicação da área de Negócios é bastante ampla e o Marketing se destaca como um impulsionador crescendo mais que proporcionalmente que os demais temas. O mesmo ocorre 
com o item Pesquisa dentro dos artigos de Marketing, demonstrando que a busca por novos caminhos incentiva os pesquisadores a encontrar caminhos que possibilitem compreender o fenômeno do turismo de forma mais ampla adicionando novos vetores de investigação.

Os pontos fracos do artigo foram a limitada amostra. Acredita-se que, mesmo assim, aprofundamentos nesta área podem servir de incentivo a outros pesquisadores. Quanto aos pontos fortes do artigo pode-se se destacar as contribuições para a academia e o campo gerencial.

Para a academia as contribuições se concentram na revelação das preferências de investigação por parte dos pesquisadores brasileiros. Quando comparados com os pesquisadores internacionais vê-se que estão bastante alinhados, embora um tanto atrasados na descoberta das pesquisas como fonte crucial de informação para o alargamento das fronteiras do setor turístico.

As contribuições para o campo gerencial ser dão no reconhecimento da evolução das pesquisas na área de Negócios e principalmente em Marketing insinuando-se que parcerias da academia com o setor privado podem ser relevantes para impulsionar mais ainda as pesquisas do setor.

Outras pesquisas estão planejadas para aprofundar o perfil da produção brasileira em Marketing Turístico, explorando como a aproximação entre as áreas pode resultar em um melhor planejamento das atividades do Turismo, Hospitalidade e Viagens em meio a uma concorrência crescente que multiplica as possibilidades de escolha para o público consumidor destes produtos.

\section{REFERÊNCIAS}

Alcañiz, J. E. B., Simó, L. A., García, I. S. \& Herrera, A. A. (2008). Investigación internacional en marketing turístico: análisis de contenido sobre temas y metodologías. Comité Editorial Director: Agustín Santana Talavera, 6, 389.

Arantes, A. C. (1975). Administração mercadológica: princípios e métodos. FGV, Instituto de Documentação, Editora da Fundação Getúlio Vargas.

Bagozzi, R. P. (1986). Principles of marketing management. Chicago: Science Research Associates.

Baker, M. J. (2000a.) Marketing - philosophy or function? In: Marketing theory: a student text. New York: Thomson Learning, 1-20.

Baker, M. J. (2000b.). The future of marketing. In: . Marketing theory: a student text. New York: Thomson Learning, 293-314. 
Bartels, R. (1976). The History of Marketing Thought. Columbus, OH: GRID. Inc.

Beni, M. C. (2006). Política e planejamento de turismo no Brasil. São Paulo: Aleph.

Bowie, D. \& Buttle, F. (2004). Hospitality marketing. An Introduction, Elsevier ButterworthHeinemann.

Buhalis, D. (2000). Marketing the competitive destination of the future. Tourism management, 21(1), 97-116.

Buhalis, D. \& Costa, C. (2006). Tourism management dynamics: trends, management and tools. Routledge.

Butler, R. S. (1914). Marketing Methods. Alexander Hamilton Institute.

Brunelli, M. D. Q., Macedo-Soares, T. D. L., Zouain, D. M. \& Borges, A. P. (2010). Scientific research in tourism: review of the literature from 2005 to 2009. Revista de Administração Pública, 44(5), 1225-1240.

Cobra, M. (1992). Administração de Marketing: A análise do mercado de consumo e o comportamento do consumidor. São Paulo: Atlas.

Cobra, M. (2001). Marketing de turismo. Marcos Cobra Editora Ltda.

Costa, C. R. F. (2008). A produção acadêmica de marketing no Brasil: uma análise historiográfica dos últimos 50 anos. Dissertação (Mestrado em Gestão de Negócios) Programa de Pós-graduação em Administração, Universidade Estadual de Maringá, Maringá.

Da Silva, S.D.A., Cipriano M.J.S. \& Matos, C.O. (2015). Marketing Turístico: um estudo sobre as ações de promoção da imagem do destino Natal/RN, Brasil. Revista Turismo y Desarollo local, 8(18).

Da Silva Flores, L. C., de Sena Cavalcante, L. \& Raye, R. L. (2012). Marketing turístico: Estudo sobre o uso da tecnologia da informação e comunicação nas agências de viagens e turismo de Balneário Camboriú (SC, Brasil). Revista Brasileira de Pesquisa em Turismo, 6(3), 322-339.

De Lima Medeiros, M., Mariutti, F. G. \& Machado, D. F. C. (2012). A Pesquisa em Marketing Turístico: uma análise da produção acadêmica apresentada no Seminário da ANPTUR de 2006 a 2010. Anais Brasileiros de Estudos Turísticos-ABET, 2(1).

Dev, C. S., Buschman, J. D. \& Bowen, J. T. (2010). Hospitality marketing: A retrospective analysis (1960-2010) and predictions (2010-2020). Cornell Hospitality Quarterly, 51(4), 459469.

Dias, R., \& Cassar, M. (2005). Fundamentos do Marketing Turístico. São Paulo, Pearson Prentice Hall.

Donaire, D., da Silva, M. P. \& Gaspar, M. A. (2009). A rede de negócios do turismo: um estudo sobre suas características e implicações estratégicas. Turismo-Visão e Ação, 11(1), 112-134. 
Firat, A. F. \& Venkatesh, A. (1993). Postmodernity: the age of marketing. International Journal of Research in Marketing, 10(3), 227-249.

Grönroos, C. (1994). From marketing mix to relationship marketing: towards a paradigm shift in marketing. Management Decision, 32(2), 4-20.

Gummesson, E. (2002). Relationship marketing and a new economy: it's time for deprogramming. Journal of Services Marketing, 16(7), 585-589.

Holloway, J. C. (2004). Marketing for tourism. Pearson education.

Hunt, S. D. (1983). General theories and the fundamental explananda of marketing. The Journal of Marketing, 9-17.

Hsu, C. H. \& Powers, T. (2002). Marketing hospitality. John Wiley and Sons.

Kastenholz, E. (2002). The role and marketing implications of destination images on tourist behavior: The case of northern Portugal. Tese (Doutorado em Turismo), Departamento de Economia, Gestão e Engenharia Industrial, Universidade de Aveiro, Aveiro.

Krippendorf, Jost. (2010). Holiday makers. Great Britain. Butterworth-Heinemann Keith, R. J. (1968). The Marketing Revolution. Journal of Marketing, 24 (3), 35-35.

Kotler, P., Bowen, J. \& Makens, J. (1998). Marketing for Hospitality and Tourism, 2nd ed. Upper Saddle River: Prentice Hall.

Kotler, P., Kartajaya, H. \& Setiawan, I. (2010). Marketing 3.0: as forças que estão definindo o novo marketing centrado no ser humano. Elsevier.

Kotler, P. \& Keller, K. L. (2012). Administração de marketing. São Paulo: Pearson

Knutson, B.J. \& Beck, J. A. (2003) Identifying the dimensions of the experience construct: development of the model. Journal of Quality Assurance in Hospitality \& Tourism, 4(3/4), 23-35.

Lage. B.H.G. \& Milone. P.C. (1990). Economia do turismo. São Paulo: Papirus. 122p.

Lazer, W. (1966). Education for marketing in the 1970s. The Journal of Marketing, 33-37.

Li, X. R. \& Petrick, J. F. (2008). Tourism marketing in an era of paradigm shift. Journal of Travel Research, 46(3), 235-244.

Lusch, R. F. (2007). Marketing's evolving identity: defining our future. Journal of Public Policy \& Marketing, 26(2), 261-268.

Machado, D. F. C., de Lima Medeiros, M. \& Luce, F. B. (2011). A miopia do marketing de destinos turísticos. Encontros Científicos-Tourism \& Management Studies, (1), 654-663.

Maynard, H. H. (1942). Early teachers of marketing. Journal of Marketing, 7(2), 158. 
Maynard, H. H. (1941). Marketing courses prior to 1910. The Journal of Marketing, 5(4), 382-384.

Medeiros, M. L.; Mariutti, F.G. \& Machado, D. F. C., de. (2011). A Pesquisa em Marketing Turístico: Uma análise da Produção Acadêmica apresentada no Seminário da ANPTUR de 2006-2010. Seminário da Associação Nacional de Pós-Graduação em Turismo, Anptur, Univali -Balneário de Camburiú/SC.

Middleton, V. T. C. \& Clarke, J. (2001) Marketing in Travel and Tourism. Oxford: Butterworth-Heinemann.

Middleton, V. T., Fyall, A., Morgan, M. \& Ranchhod, A. (2009). Marketing in travel and tourism. Oxford: Routledge.

Moretti, S. L.A., A Encontros de hospitalidade, experiência de consumo e relacionamento com clientes: proposta preliminar para sua integração In: Seminário da Associação Nacional de Pós-Graduação em Turismo, Anptur, 12, 2015, Natal.

Moretti, S. L. A. \& Toledo, G. L. (2015). Marketing and Sustainability Academic Production in brazil: An analysis in leading management journals during the period of 1994-2012. . Business and Management Review. Special issue, 616- 630.

Morrison, A. M. (2012). Marketing de hospitalidade e turismo. Cengage Learning, São Paulo.

Oliveira, S. L. I. (2007). Desmistificando o marketing. Novatec Editora.

Panosso Netto, A. (2009). Segmentação em turismo: panorama atual. In. PANOSSO NETTO, Alexandre; ANSARAH, Marília GR. Segmentação do mercado turístico: estudos, produtos e perspectivas. Barueri: Manole, 19-43.

Pereira, L.M., Leite, M. H. R. \& Flores, L.,C.S. (2013). Analise da Orientação para o Marketing: avaliação de unidades hoteleiras em Balneário de Camboriú/SC e em Foz de Iguaçu/PR. Seminário da Associação Nacional de Pós-Graduação em Turismo, Anptur, Universidade Caxias do Sul.

Pike, S. (2008). Destination Marketing: An integrated marketing communication approach. Oxford: Elsevier.

Robinson, M. \& Paul Lynch, P. (2007). The Power of Hospitality: A Sociolinguistic Analysis. In Lashley, C., Lynch, P. A., Morrison, A. (Eds), Hospitality: A Social Lens, Oxford: Elsevier.

Sandhusen, R. L. (2003). Marketing Básico. 2a . São Paulo: Saraiva.

Sheth, J. N., Gardner, D. M. \& Garrett, D. E. (1988). Marketing theory: evolution and evaluation, 1. New York, NY: Wiley.

Silva, E. G. (2010). O espectador doméstico e os novos canais de acesso: uma análise dos hábitos da audiência de produtos audiovisuais. Dissertação (Mestrado) - Universidade Nove Pós-Graduação em Administração de Empresas. 
Smithee, A. (1997). Kotler is dead! European Journal of Marketing, Wagon Lane, 3 (3), $317-$ 325 .

Srivastava, R. K., Shervani, T. A. \& Fahey, L. (1999). Marketing, business processes, and shareholder value: An organizationally embedded view of marketing activities and the discipline of marketing. The Journal of Marketing, 168-179.

Surface, A. \& E. Alderson. (1940) Marketing. Boston: Ginn and Company.

Toledo, G.L. (1994). Relações públicas e marketing: um conceito tridimensional. Anais do XVIII EnANPAD, 145-157, Curitiba.

Toledo, G. L. \& Moretti, S.L.A. (2016). Valor para o cliente e valor do cliente: conceitos e implicações para o processo de marketing. Artigo aprovado para Desenvolvimento em Questão, 14 (345).

Tosun, C., Okumus, F. \& Fyall, A. (2008). Marketing Philosophies: Evidence from Turkey. Annals of Tourism Research, 35(1), 127-147.

Trigueiro, C. M. (1999). Marketing e Turismo: como planejar e administrar o marketing turísticopara uma localidade. Rio de Janeiro: Qualitymark.

Vargo, S. L. \& Lusch, R. F. (2004). Evolving to a new dominant logic for marketing. Journal of Marketing, 68(1), 1-17.

Von Friedrichs, Grängsjö, Y., \& Gummesson, E. (2006). Hotel networks and social capital in destination marketing. International Journal of Service Industry Management, 17(1), 58-75.

Wilkie, W. L. \& Moore, E. S. (2003). Scholarly research in marketing: Exploring the "4 eras" of thought development. Journal of Public Policy \& Marketing, 22(2), 116-146. 